\title{
Mulheres Doadoras de Leite Humano*
}

\author{
Reasons Women donate breast milk
}

Mujeres donantes de leche bumana

\author{
Marli Teresinha Gimeniz Galvão ${ }^{1}$, Simone Gonçalves Vasconcelos ${ }^{2}$, Simone de \\ Sousa Paiva ${ }^{3}$
}

\begin{abstract}
RESUMO
Objetivos: verificar algumas variáveis do perfil sócio-demográfico de doadoras de leite humano no Banco de Leite e identificar as razões que as fazem doar seu leite. Métodos: estudo exploratório de caráter descritivo, com abordagem qualitativa, realizado em maio de 2003 com 11 doadoras de leite humano em maternidade pública de Fortaleza-CE. Para coleta de dados utilizou-se formulário semi-estruturado. Resultados: a maioria apresentava idade entre 16 e 20 anos, eram casadas, possuíam instrução do ensino fundamental até o universitário. O motivo que levou as nutrizes a doar seu leite era o ingurgitamento mamário e eram encaminhadas por profissionais de saúde. A maioria desconhecia os benefícios proporcionados pelo aleitamento materno para a mãe e filho, bem como a importância do Banco de Leite. Considerações finais: sugere-se que as mulheres em geral devem receber informações a respeito dos benefícios e importância do aleitamento natural, incluindo informações sobre doação do leite humano, mediante os bancos de leite.
\end{abstract}

Descritores: Bancos de leite; Leite humano; Aleitamento materno

\begin{abstract}
Objective: to determine the socio-demographic profile of human milk donors and to identify the reasons they choose to donate their milk. Methods: this was an exploratory, descriptive, and qualitative study. Eleven women from a public maternity hospital in Fortaleza, Ceará, participated in this study. Data were collected in May 2003 using a semi-structured questionnaire. Results: milk donors were 16 to 20 years old, married, and had an educational level ranging from elementary school to college. Women reported that the main reasons for donating their milk were breast engorgement and referral by health professionals. The most donors were not aware of the benefits of breast-feeding or the importance of their contribution to the maternity hospital milk bank. Final considerations: women should receive information about the benefits of breast feeding and donation of human milk through milk banks.
\end{abstract}

Keywords: Milk banks; Milk human; Breast feeding

\section{RESUMEN}

Objetivos: se tuvo como objetivos verificar algunas variables del perfil socio-demográfico de donantes de leche humana en el Banco de Leche e identificar las razones que las llevan a donar su leche. Métodos: estudio exploratorio de carácter descriptivo, con abordaje cualitativo, realizado en mayo del 2003 con 11 donantes de leche humana en una maternidad pública de Fortaleza-CE. Para la recolección de datos se utilizó un formulario semi-estructurado. Resultados: la mayoría tenía edades comprendidas entre los 16 y 20 años, casadas, poseían instrucción de enseñanza fundamental. El motivo que llevó a las nutrices a donar su leche fue la turgencia mamaria siendo encaminadas por profesionales de salud. La mayoría desconocía los beneficios proporcionados por la lactancia materna tanto para la madre como para el hijo, así como la importancia del Banco de Leche. Consideraciones finales: se sugiere que las mujeres, en general, reciban informaciones respecto a los beneficios e importancia de la lactancia natural, incluyendo informaciones sobre donación de la leche humana mediante los bancos de leche.

Descriptors: Bancos de leche; Leche humana; Lactancia materna

\footnotetext{
*O trabalho foi extraído de uma Monografia de conclusão do curso de Graduação em Enfermagem da Universidade Federal do Ceará - UFC - Ceará (CE). ${ }^{1}$ Enfermeira. Professora Doutora do Departamento de Enfermagem e do Curso de Pós-Graduação em Enfermagem da Universidade Federal do Ceará - UFC - Ceará (CE), Brasil.

${ }^{2}$ Enfermeira.. Mestranda do Curso de Pós-Graduação em Enfermagem da Universidade Federal do Ceará - UFC - Ceará (CE), Brasil..

${ }^{3}$ Discente do $9^{\circ}$ Semestre do Curso de Graduação em Enfermagem da Universidade Federal do Ceará - UFC - (CE), Brasil. Membro do Grupo de Pesquisa Auto-Ajuda para o Cuidado de Enfermagem-CNPq. Bolsista CNPq.
} 


\section{INTRODUÇÃO}

Ao longo da história, a amamentação teve diferentes significados e foi alvo de interesse de vários grupos sociais. Influenciada fortemente por fatores socio-culturais, nenhuma função humana foi tão agredida e artificializada quanto a amamentação, e hoje o aleitamento materno é apenas uma das opções de alimentação para o recémnascido. Isso acarreta aumento significativo nos quadros de desnutrição e mortalidade infantil ${ }^{(1)}$.

O leite humano é de grande valor para o recémnascido e para o lactente por conter, em proporções adequadas, os nutrientes necessários para o início da vida, além de apresentar melhores condições de digestibilidade para o trato intestinal, ainda imaturo. Também propicia nutrição de alta qualidade para a criança, contribuindo para seu crescimento e desenvolvimento. Tem sido responsável pela redução da morbi-mortalidade infantil. As frações de mortalidade evitável por amamentação ultrapassam os $60 \%$ e os $80 \%$, respectivamente, para os casos de infecção respiratória e de diarréia, as duas principais causas de óbito após o período neonatal precoce $^{(2)}$.

É indiscutível o benefício advindo do leite materno. Dentro deste contexto, considera-se imprescindível dispor de leite humano, em quantidades que permitam o atendimento, nos momentos de urgência, a todos os lactentes que, por motivos clinicamente comprovados, não disponham de aleitamento ao seio, situação essa para qual os Bancos de Leite Humano (BLH) constituem uma solução.

Segundo o Ministério da Saúde, doadoras de leite humano são nutrizes sadias que apresentam secreção láctea superior às exigências do seu filho, e que se dispõem a doar, por livre e espontânea vontade, o excesso de leite produzido. Para ser doadora, a nutriz deverá ser submetida a exame clínico detalhado, com finalidade de proteger a sua saúde e a do receptor ${ }^{(3)}$.

As doações voluntárias são indispensáveis para dar continuidade ao projeto dos $\mathrm{BLH}$, os quais viabilizam a manutenção do aleitamento natural para grupos alvo, constituídos, principalmente, por recém-nascidos prematuros de baixo peso e com outras intercorrências.

Define-se BLH como um centro especializado responsável pela promoção do incentivo ao aleitamento materno e execução das atividades de coleta, processamento e controle de qualidade de colostro, leite de transição e leite maduro, com vistas à posterior distribuição para crianças que dele necessitam como fator de sobrevivência ${ }^{(4)}$.

Diante do exposto, teve-se como objetivos verificar algumas variáveis relacionadas ao perfil sóciodemográfico de doadoras voluntárias de leite humano no Banco de Leite e identificar as razões que as fazem doar seu leite.

\section{METODOS}

Trata-se de pesquisa exploratória, de caráter descritivo, com abordagem qualitativa. A pesquisa qualitativa combina a natureza científica e artística da enfermagem para aumentar a compreensão da experiência de saúde humana, estuda coisas em seus cenários naturais, tentando compreender ou interpretar fenômenos em termos dos significados que as pessoas trazem para eles ${ }^{(5)}$.

Participaram da pesquisa 11 mulheres doadoras voluntárias, cadastradas em um banco de leite humano e que compareceram para doação em um hospital público de Fortaleza-CE em maio de 2003.

O número de participantes foi definido pela saturação de dados e, coincidentemente, correspondeu ao total de mulheres que voluntariamente doavam o leite humano no mês de maio.

Os critérios utilizados para a seleção das participantes foram os seguintes: doar espontaneamente seu leite em benefício de outras crianças e aceitar participar da pesquisa. Foram excluídas aquelas que doavam leite humano em prol da saúde do seu próprio filho.

Para a coleta de dados foi utilizado um formulário semi-estruturado que permitia obter a caracterização das mulheres, e apresentava questões norteadoras: Quais os motivos que fizeram a senhora procurar o BLH? Como o seu leite chega a outro recém-nascido? O que sabe sobre o aleitamento materno? Desta forma buscava-se o motivo ou razões da procura do BLH para doar o próprio leite. As entrevistas foram efetuadas em sala individual e anotadas literalmente pelo pesquisadora.

Os dados de caracterização foram analisados em números absolutos e relativos. Para interpretação das informações obtidas pelas questões abertas, utilizou-se a análise de conteúdo ${ }^{(6)}$. As informações relevantes contidas nas respostas foram identificadas e extraídas, com vistas a obter informações sobre a doação de leite; os dados foram classificados, segundo características comuns ou feixes de relação, e deram origem às seguintes categorias: Motivo do início da doação do leite; Des-conhecendo o banco de leite humano; Importância do banco de leite; Importância do leite natural.

O projeto cumpriu todas as exigências da Resolução $n^{\circ}$ 196, de 10 de outubro de 1996, do Conselho Nacional de Saúde, sobre pesquisa envolvendo seres humanos. Será utilizada a letra "E" para apresentação das falas das entrevistadas.

\section{RESULTADOS}

\section{Caracterização das mulheres}

A Tabela 1 apresenta as características 
sociodemográficas das nutrizes doadoras de leite humano. Conforme se observou, a maioria apresentava idades entre 16 e 20 anos, faixa em que ocorre maior numero de nascimentos.

Quanto à situação conjugal, as mulheres doadoras quase na totalidade eram casadas e possuíam escolaridade variável desde o ensino fundamental, equivalente ao primário completo ou incompleto, até o universitário. Em relação à situação funcional, a maioria delas desempenhava função de trabalhadora. Depreende-se que, embora exerçam uma função fora de casa as nutrizes encontraram estímulo para amamentar seus filhos, e ainda doar o excesso do seu leite em beneficio de outras crianças necessitadas.

Com referência à renda familiar, uma das mulheres mencionou não possuir rendimentos, vivendo com auxílio de doações voluntárias de amigos, vizinhos e parentes, quatro indicaram renda menor que dois salários mínimos (o salário mínimo vigente na época era de duzentos e quarenta reais), enquanto as demais informaram renda familiar entre dois e quatro salários.

$\mathrm{Na}$ análise das falas, as categorias retrataram desde o interesse até o conhecimento da nutriz sobre os diversos aspectos que envolvem a doação do leite humano.

TABELA 1: Caracterização das mulheres doadoras de leite em um banco de leite humano, Fortaleza, 2003

\begin{tabular}{llcr}
\hline Características & & $\mathbf{N}^{\mathbf{o}}$ & \multicolumn{1}{c}{$\mathbf{0}$} \\
\hline Idade & $16-20$ & 6 & 54,5 \\
& $21-30$ & 4 & 36,4 \\
Situação Conjugal & $31-40$ & 1 & 9,1 \\
& & & \\
& Casada & 10 & 90,9 \\
& Solteira & 1 & 9,1 \\
Situação Funcional & & & \\
& Empregada & 5 & 45,5 \\
& Dona de Casa & 3 & 27,3 \\
& Estudante & 2 & 18,1 \\
& Desempregada & 1 & 9,1 \\
Grau de Instrução & & & \\
& Ens. Fund. Incompleto & 4 & 36,4 \\
& Ens. Fund Completo & 2 & 18,2 \\
& Ens. Médio Incompleto & 2 & 18,2 \\
& Ens. Médio Completo & 2 & 18,2 \\
& Ens. Superior completo & 1 & 9,1 \\
Renda Familiar (Salário Mínimo) & & \\
& < 2 & 4 & 36,3 \\
& 2 - 4 & 5 & 45,5 \\
& Sem Rendimento & 1 & 9,1 \\
& Sem Informação & 1 & 9,1 \\
\hline & &
\end{tabular}

\section{Motivo do início da doação do leite}

O motivo da doação do leite decorreu das conseqüências do ingurgitamento mamário, e as doadoras foram incentivadas pelo aconselhamento de profissionais que atendiam no pós-parto.

O fenômeno do ingurgitamento mamário ocorre pelo congestionamento venoso e linfático da mama e pela estase láctea em qualquer das porções do parênquima, lobular, lobar, ampolar ou toda região glandular ${ }^{(7)}$.

Para o alívio do ingurgitamento recomenda-se extração do leite que está congestionando a mama, por meio da amamentação direta ao recém-nascido. Se após a satisfação do bebê ainda houver tumefação da mama, o alívio se dá pela retirada manual do leite materno. Neste aspecto, os depoimentos das nutrizes, a seguir, retratam essa motivação.

Estou doando porque o meu peito está cheio e duro, o bebê não dá conta ... então resolvi doá-lo.... (E.5)

... me falaram que o leite doado é para os bebês que precisam, estava em excesso... então dôo... (E.7)

A procura pelo BLH foi motivada inicialmente por desconforto decorrente do ingurgitamento. Sua conseqüência, porém, foi a doação voluntária mais constante do leite. Ao recorrerem ao serviço, as nutrizes recebiam informações sobre a importância e o benefício proporcionado pelo seu leite e, assim, mostraram-se mais dispostas a dar continuidade à doação em prol da saúde de outros recém-nascidos.

\section{Des-conhecendo os objetivos do Banco de Leite Humano}

Segundo a maioria das nutrizes, elas tomaram conhecimento da existência do Banco de Leite somente no período pré-natal ou após o parto. As falas das mulheres expressam essa informação.

... só soube da existência de banco de leite quando eu estive na maternidade para parir...(E.4)

... Banco de leite, eu vim saber durante as orientações no prénatal".(E.2)

A ausência de informações sobre os diferentes objetivos do BLH gera desconhecimento, como pode ser constatado na fala a seguir.

...sabia que o banco de leite era para coleta de leite das mães...cujos filhos estavam internados... (E. 2)

De acordo com este comentário, embora já tenham ouvido falar sobre o Banco de Leite, as orientações apreendidas no pré-natal limitavam-se a um serviço que recebia leite apenas da mãe para o filho. Neste contexto, pode-se inferir que os objetivos divulgados pelo Ministério da Saúde são pouco conhecidos. Entretanto, um dos objetivos do Banco de Leite é operacionalizar, de forma otimizada, o excedente da produção láctea de cada nutriz, bem como desempenhar papel educativo ${ }^{(4)}$.

O leite doado beneficia desde recém-nascidos prétermo, até crianças que necessitam do leite materno como forma de suprir deficiências nutricionais.

Como mostraram os depoimentos das mulheres, à medida que se apresentavam para a doação, os objetivos divulgados pelo Ministério da Saúde tornavam-se mais claros, pois ficavam sabendo mais a respeito do destino 
do seu leite, e o quanto beneficiavam outras crianças. Algumas falas, a seguir, justificam esse conteúdo: (E. 1)

O leite épara outros bebês que precisam... correm risco de vida...

O men leite excedente vai servir para crianças doentes... internadas...(E. 6)

\section{Importância do leite natural}

O Banco de Leite cumpre papel importante na manutenção do aleitamento materno por meio das orientações dadas, tanto sobre os benefícios como sobre a forma correta de amamentar, evitando, assim, o desmame precoce.

A propaganda e os apelos publicitários para a introdução de leite industrializado no lactente constituem poderoso veículo formador de opinião, na tentativa de convencer a população e a classe médica dos benefícios do leite artificial e incentivá-los ao desmame precoce do aleitamento materno. Mas o leite materno é insubstituível, e o impacto mais modesto de um programa de aleitamento materno reduz em até $13 \%$ o Coeficiente de Mortalidade Infantil ${ }^{(2)}$.

As falas a seguir evidenciam a importância do aleitamento para as mulheres:

É o melhor alimento para o bebê... (E. 7); ... previne infecções...(E. 6)

...ajuda o bebê a crescer forte... (E. 3); ... deve ser dado no minimo até seis meses... (E. 1)

Além disso, algumas doadoras referiram outros motivos para amamentarem.

Dou o peito porque os bebês sentem fome. (E. 5)

Dižem que é bom para o bebê. (E. 8; 10)

\section{DISCUSSÃO}

Em decorrência da ausência de investigação na literatura sobre doadoras voluntárias de leite humano, que pudessem corroborar com os achados de caracterização das mulheres estudadas, os dados obtidos permitem apontar que as doadoras do estudo viviam em lares empobrecidos pois, segundo informaram, uma não tinha qualquer rendimento, enquanto outras possuíam renda familiar muito aquém das exigências atuais, para sobreviver mais dignamente. Entretanto, sentiam-se motivadas a doar o excesso de um alimento essencial, em prol da vida de outros.

O maior motivo para doação do leite foi o desconforto de um ingurgitamento mamário. Com vistas à ampliação do número de doadoras voluntárias de leite e à continuidade destas doações, há necessidade de freqüentes orientações repassadas pela equipe de saúde, principalmente do Banco de Leite, a respeito da importância das doações e do aleitamento materno. Conforme divulgado, o número de doadoras vem crescendo gradativamente. Em 2003 aumentou em 34,5\% comparativamente a anos anteriores ${ }^{(8)}$.

O leite humano é infinitamente superior a qualquer outro e por isso os bancos são indispensáveis e devem ser bem administrados e bem cuidados ${ }^{(4)}$. No entanto para a manutenção dos mesmos, é preciso contar com doação voluntária do leite de nutrizes.

Apesar da importância da captação de leite humano em BLH para a sobrevivência de inúmeros recémnascidos, a divulgação sobre o tema é ainda restrita. As informações ocorreram apenas no processo de maternidade da mulher, quando elas estão preocupadas principalmente com seu filho, e não conseguem atentar para a importância do leite para doação.

É descrita como fator importante para o aumento no número de doações de leite humano, a veiculação pelos diferentes meios de comunicação acerca do BLH, enfatizando suas características e benefícios para a população.

As respostas sobre a importância do aleitamento materno foram pontuais, e sugerem deficiência de um conhecimento mais abrangente sobre a importância do aleitamento materno, vantagens em relação a outros alimentos e adequação ao bebê em seus primeiros meses de vida, embora essas informações sejam freqüentemente divulgadas por profissionais. Segundo pesquisa, equipes treinadas conseguiram obter crescimento de até $29 \%$ do aleitamento natural em comparação a equipes não treinadas, indicando a necessidade de capacitação dos profissionais de saúde para obter êxito em suas orientações acerca da importância da amamentação natural exclusiva $^{(9)}$.

O aleitamento materno, entretanto, pode encontrar alguns obstáculos para sua prática, a exemplo do significado atribuído pela mulher ao ato de amamentar, construído por sua representação social e pela experiência pessoal da nutriz, além do apoio social disponível, condição biológica e psíquica da mulher ${ }^{(9)}$. É fundamental a preparação do profissional de saúde para cuidar das nutrizes, mediante adoção de tecnologia comunicativa centrada na pessoa para promover o conhecimento adequado sobre a necessidade de amamentar e, quando possível, doar o leite materno.

\section{CONSIDERAÇÕES FINAIS}

A doação de leite humano é essencial para a garantia de leite destinado a crianças que dele necessitam. Mas o Banco de Leite ainda é pouco conhecido, conforme evidenciado, pois a grande maioria das nutrizes participantes do estudo, foi encaminhada por profissionais.

Em relação ao perfil sócio-demográfico das doadoras foi interessante observar o quanto eram jovens, a maioria casadas, possuíam instrução do ensino fundamental até 
o universitário e todas eram provenientes de classe menos favorecida. Este dado suscita diversas indagações, como se formula: Mulheres em situação social pouco favorecida são mais sensíveis aos problemas sociais? Nutrizes de classe social mais privilegiada desconhecem a existência de BLH? Neste ínterim outras pesquisas poderão ser desenvolvidas para esclarecer estas perguntas, além de apresentar outros dados sobre nutrizes, já que são escassas matérias na literatura que demonstrem informações sobre doadoras de leite humano.

Conforme se constatou, o principal motivo das doações foi o ingurgitamento mamário e a maioria das doadoras desconhecem os benefícios e importância do aleitamento materno. Assim, pelo gesto de carinho e humanidade na condição de doadora de leite humano, a nutriz deve ser valorizada, deve ser acolhida com dignidade e respeito.

Ademais, os motivos que levaram estas nutrizes a doarem seu leite foram decorrentes da situação de desconforto, assim urge a necessidade de profissionais de saúde engajarem-se na promoção do aleitamento materno, incluindo orientações sobre o BLH.

Neste contexto, o profissional de enfermagem pode desempenhar papel importante para a manutenção do Banco de Leite, divulgando o serviço para as mulheres, independentemente de serem gestantes, além de incentivar a nutriz a amamentar seu filho e doar o leite excedente.

\section{REFERÊNCIAS}

1. Souza LMBM, Almeida JAG. História da alimentação do lactente no Brasil: do leite fraco à biologia da excepcionalidade. Rio de Janeiro: Revinter; 2005.

2. Escuder MML, Venancio SI, Pereira JCR. Estimativa de impacto da amamentação sobre a mortalidade infantil. Rev Saúde Pública. 2003; 37(3): 319-25.

3. Brasil. Ministério da Saúde. Recomendações técnicas para funcionamento de bancos de leite humano. Brasília: Ministério da Saúde, 1987.

4. Brasil. Ministério da Saúde. Normas gerais para Bancos de Leite Humano. 2a ed. Brasília: Ministério da Saúde; 1998.

5. Cabral IV, Tyrrell MAR. O objeto de estudo e a abordagem de pesquisa qualitativa na enfermagem. In: Gauthier JHM, et al. Pesquisa em enfermagem: novas metodologias aplicadas. Rio de Janeiro: Guanabara Koogan; 1998. p. 18-29.

6. Bardin L. Análise de conteúdo. Lisboa: Edições 70; 1979.

7. Schmitz EMR. A enfermagem em pediatria e puericultura. São Paulo: Atheneu; 1995.

8. Bancos de Leite Humano - Produção Brasil: 2003. Produtos e processos[ texto na Internet]; [citado 2005 Fev 24]. Disponível em: http://www.redeblh.fiocruz.br/indexphp? pagina $=$ port $/$ blh2003.htm\&men $=4 \&$ submen $=18$

9. Rezende MA, Sigaud CHS, Veríssimo MDOR, Chiesa AM, Bertolozzi MR. O processo de comunicação na promoção do aleitamento materno. Rev Latinoam Enfermagem. 2002; 10(2); 234-8. 